\title{
Priority topics for European multidisciplinary guidelines on the management of chronic kidney disease in older adults
}

DOI:

10.1007/s11255-016-1257-4

\section{Document Version}

Accepted author manuscript

Link to publication record in Manchester Research Explorer

\section{Citation for published version (APA):}

van der Veer, S. N., van Biesen, W., Bernaert, P., Bolignano, D., Brown, E. A., Covic, A., Farrington, K., Jager, K. J., Kooman, J., Macías-Núñez, J. F., Mooney, A., van Munster, B. C., Topinkova, E., Van Den Noortgate, N. J. A., Wirnsberger, G., Michel, J-P., \& Nistor, I. (2016). Priority topics for European multidisciplinary guidelines on the management of chronic kidney disease in older adults. International urology and nephrology, 48(6), 859-69. https://doi.org/10.1007/s11255-016-1257-4

\section{Published in:}

International urology and nephrology

\section{Citing this paper}

Please note that where the full-text provided on Manchester Research Explorer is the Author Accepted Manuscript or Proof version this may differ from the final Published version. If citing, it is advised that you check and use the publisher's definitive version.

\section{General rights}

Copyright and moral rights for the publications made accessible in the Research Explorer are retained by the authors and/or other copyright owners and it is a condition of accessing publications that users recognise and abide by the legal requirements associated with these rights.

\section{Takedown policy}

If you believe that this document breaches copyright please refer to the University of Manchester's Takedown Procedures [http://man.ac.uk/04Y6Bo] or contact uml.scholarlycommunications@manchester.ac.uk providing relevant details, so we can investigate your claim.

\section{OPEN ACCESS}




\section{Priority topics for European multidisciplinary guidelines on the management of chronic kidney disease in older adults}

Sabine N. van der Veer ${ }^{\mathrm{a}}$, Wim van Biesen ${ }^{\mathrm{a}, \mathrm{b}}$, Pascale Bernaert ${ }^{\mathrm{c}}$, Davide Bolignano ${ }^{\mathrm{a}, \mathrm{d}}$, Edwina A. Brown ${ }^{\mathrm{e}}$, Adrian Covic ${ }^{\mathrm{f}}$, Ken Farrington ${ }^{\mathrm{g}}$, Kitty J. Jager ${ }^{\mathrm{h}}$, Jeroen Kooman ${ }^{\mathrm{i}}$, Juan F MacíasNúñez ${ }^{\mathrm{j}}$, Andrew Mooney ${ }^{\mathrm{k}}$, Barbara C. van Munster ${ }^{\mathrm{l}}$, Eva Topinkova ${ }^{\mathrm{m}}$, Nele JA Van Den Noortgate $^{\mathrm{n}}$, Gerhard Wirnsberger ${ }^{\mathrm{m}}$, Jean-Pierre Michel $^{\mathrm{o}}$, Ionut Nistor ${ }^{\mathrm{a}, \mathrm{f}}$

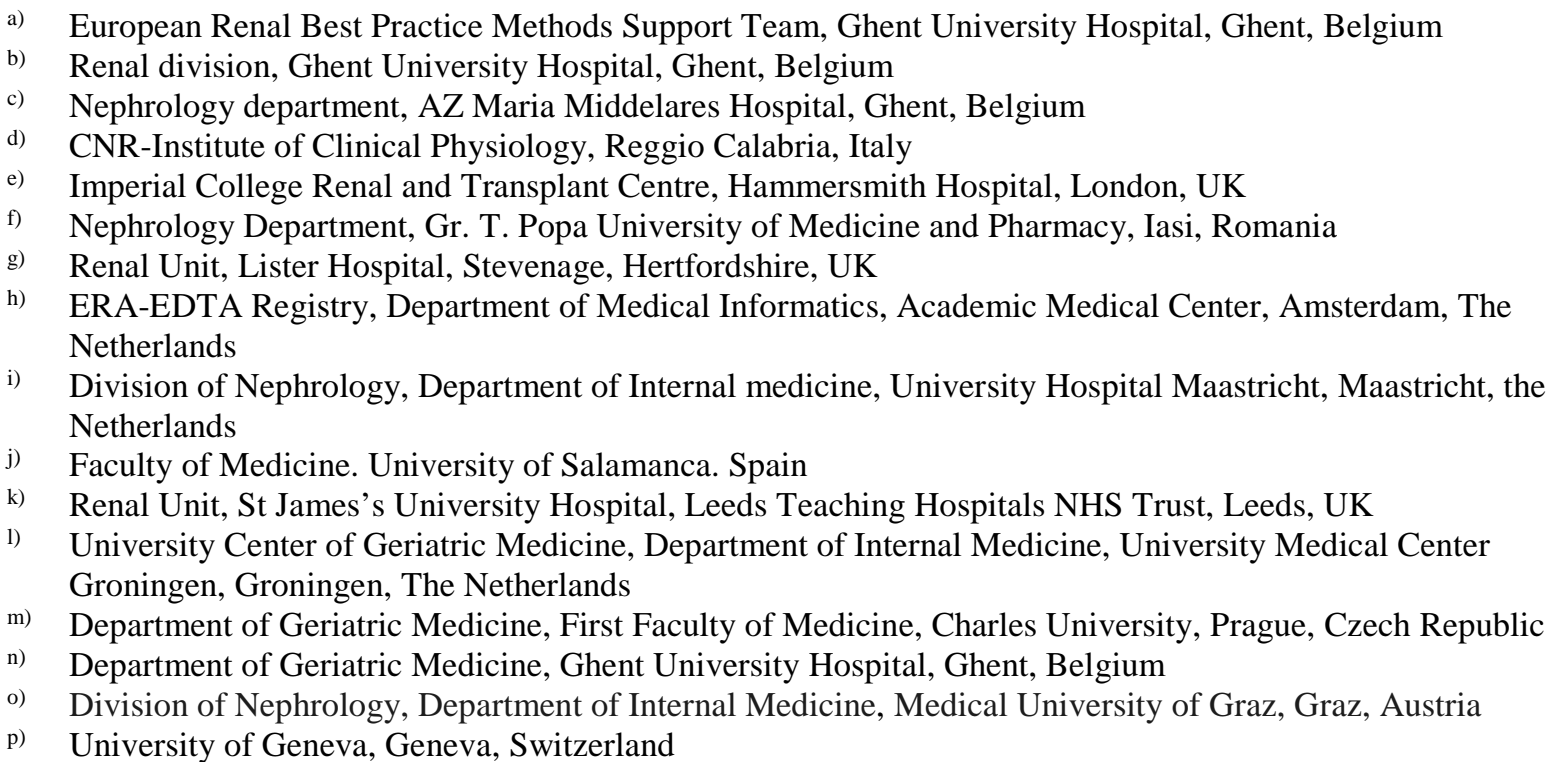

\section{Corresponding author}

Sabine $\mathrm{N}$ van der Veer

Phone + +441613067767

E-mail_sabine.vanderveer@manchester.ac.uk

Address Health eResearch Centre @ Farr Institute for Health Informatics Research

University of Manchester

Vaughan House

Portsmouth Street

Manchester M13 9GB

United Kingdom 


\section{Abstract}

Purpose To identify and prioritize potential topics to be addressed in the development of European, multidisciplinary guidelines on the management of chronic kidney disease stage 3b to 5 in older patients.

Methods We composed a list of 47 potential guideline topics by reviewing the literature, consulting online 461 nephrologists and 107 geriatricians, and obtaining expert input. A multidisciplinary panel of twelve experts then prioritized the topics during a face-toface consensus meeting, following a Nominal Group Technique structure with two voting rounds. Topics were rated on a 9-point scale ranging from 1 ('not at all important') to 9 ('critically important').

Results The highest rating (median; range) was assigned to 'Screening and referral' (8.5; 2.0). Eight topics shared the second highest rating with a median priority score of 8.0 (2.0), and included 'Starting dialysis or not' and 'Accurate assessment of renal function'. 'Targets for and treatment of diabetes' received the lowest rating with (3.0; 6.0).

Conclusions This joint initiative of the European Renal Association - European Dialysis Transplant Association (ERA-EDTA) and the European Union Geriatric Medicine Society (EUGMS) prioritized the development of guidance on interdisciplinary referral of older patients with chronic kidney disease stage 3b to 5. Future guidance will therefore focus on identifying prognostic scores to predict death and progression to end-stage renal disease, as well as accurate tests for assessment of renal function in older kidney patients. This will contribute to more informed treatment decision-making in this growing patient population.

Keywords: Aged; Aged, 80 and over; Renal insufficiency, chronic; Practice guidelines as topic; Consensus 


\section{Introduction}

The prevalence of old age among patients with chronic kidney disease (CKD) is increasing [1-3], as is the number of older people in the general population who meet the criteria for CKD $[4,5]$. Nephrologists and geriatricians providing care for these patients are often confronted with a complex decision-making process in which reduced kidney function, multimorbidity, polypharmacy, malnutrition, physical and cognitive frailty, limited life expectancy, and reduced quality of life are likely to affect the harm-benefit balance of treatments. This implies that choices around, for example, prescribing angiotensin-converting enzyme inhibitors [4], preparing for and starting of renal replacement therapy [6], or the type of vascular access for maintenance hemodialysis [7] may be deliberated differently compared to treatment decisions in patients who are younger.

Although clinical practice guidelines aim to support treatment decision making, previous research suggested that many chronic disease guidelines may not apply to older and multimorbid patients $[8,9]$. This is also true for CKD: despite the apparent need for a distinct decision-making approach, international guidelines addressing overall CKD management in older people are still lacking.

Therefore, the European Renal Association - European Dialysis Transplant Association (ERA-EDTA) and the European Union Geriatric Medicine Society (EUGMS) joined forces to develop such guidelines. As a first step in the development process, European Renal Best Practice (ERBP, the official guideline-writing body of the ERA-EDTA) initiated a study to identify those topics which should be covered by the guidelines. In addition to setting priorities for guideline development, the results of this study will contribute to shaping a European research agenda on how to improve care in older CKD patients. 


\section{Methods}

The general objective of the new guidelines will be to inform clinical decisions and practices related to managing CKD stage $3 \mathrm{~b}$ to 5 in older patients. It will concern decisions or practices that may be different between older and younger CKD patients, or between older patients with and without CKD. With this general objective in mind, we carried out a scoping process to identify and prioritize topics to be addressed in the guidelines (Figure 1). We used a broad definition of 'older', i.e., aged 65 years and above. Throughout the process, we received input from an international expert panel consisting of eight nephrologists and five geriatricians from Austria, Belgium, Czech Republic, Italy, Romania, Spain, the Netherlands, and the United Kingdom; all were recruited via the professional networks of ERBP and EUGMS.

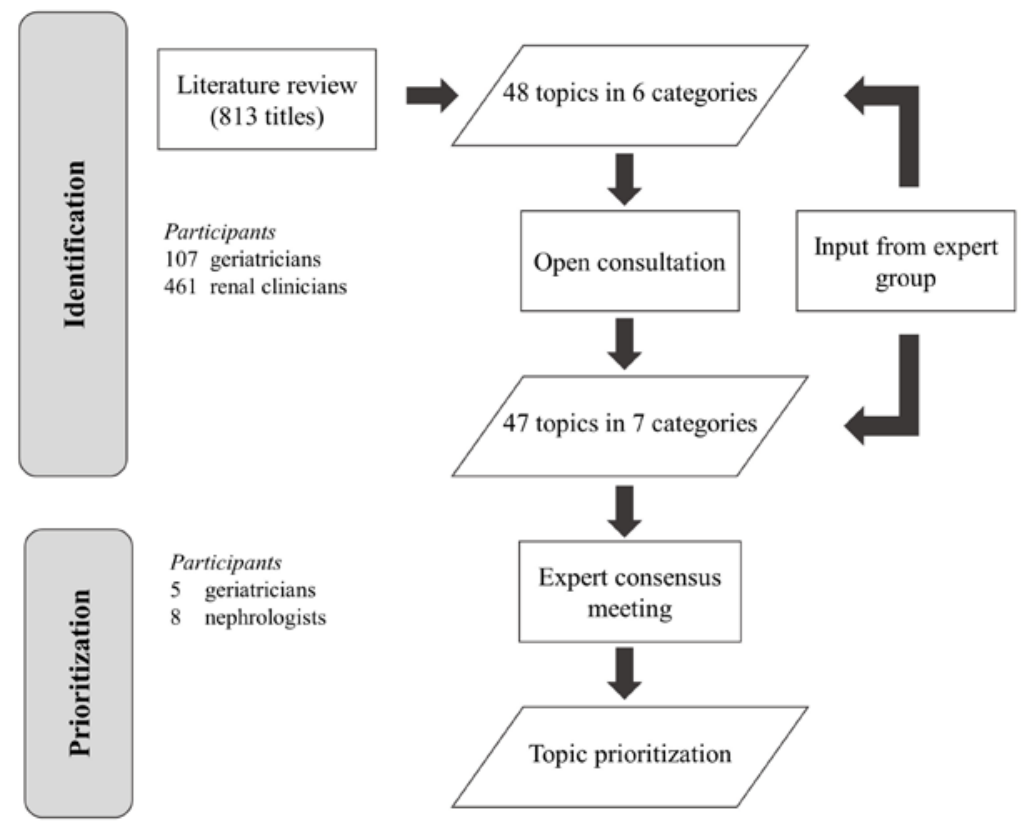

Figure 1 Process of identifying and prioritizing guideline topics

\section{$\underline{\text { Identifying topics - Literature review and open consultation }}$}

We first explored those topics relating to CKD care in older people which have been commonly addressed in published studies and guidelines. We searched Cochrane's central register of controlled trials (CENTRAL), and Medline via Ovid for geriatric guidelines; the 
syntax is provided in Appendix A. Based on title and abstract, two reviewers (SvdV and IN) extracted the primary topic of each publication. They also hand searched the tables of content of geriatrics journals listed in Medscape for the period June 2012 to August 2013. The findings of the exploratory review were complemented by the views of the expert panel, which resulted in the identification of a preliminary list consisting of 48 topics (Appendix B) in six categories. These were: Assessment of renal function and diagnosis of renal impairment; Management of symptoms related to CKD stage 3b-5; Management of comorbidities; Decisions around treatment selection; Renal replacement therapy; Conservative (non-dialytic) management of end-stage renal disease.

Standards for guideline development advocate target user involvement in early stages of the development process $[10,11]$ to optimize guidelines’ relevance for clinical practice. Therefore, we organized an open, online consultation among geriatricians and nephrologists. We developed an electronic, English language questionnaire in SurveyMonkey® that presented all 48 topics from the preliminary list (Appendix B). Within each of the six categories, we asked respondents to select the $50 \%$ of topics that they assigned highest priority for guideline development. At the end of the questionnaire, they could suggest additional topics not yet in the list. Members of our expert panel (BvM, EB, IN, JPM, WvB) pilot-tested the questionnaire for clarity and ease of completion. We disseminated the questionnaire via an undirected email blast to members of the ERA-EDTA, via a link on the EUGMS website, and through the professional networks of our experts.

The expert panel then reviewed all suggestions for additional topics, and based on this we added one category ('General patient management') and five topics (marked as such in Table A), and merged, split and/or renamed several existing topics. The final topic list consisted of 47 items in seven categories (Table A).

Prioritizing topics - Expert consensus meeting 
To prioritize the 47 topics, twelve of the thirteen experts attended a full-day face-to-face meeting, moderated by a nephrologist who was not a member of the panel (WvB). The meeting followed a Nominal Group Technique structure [12], and included an introductory part and two rounds of priority rating. In the introduction, the moderator presented the priorities as reported in the open consultation (Appendix B), and revisited the 47 topics to ensure all experts interpreted them in a similar manner. To align the concept of 'priority' within the panel we provided cues [12] characterising high priority topics as decisions or practices: (1) that were common in clinical practice; (2) that strongly affected patient outcomes; (3) for which there was uncertainty or disagreement around optimal care; or (4) that may be associated with substantial risk of patient harm (e.g., adverse events) or high costs for the healthcare system [11].

In the first round of priority rating, individual experts anonymously rated all topics on an ordinal 9-point scale ranging from 1 ('not at all important') to 9 ('critically important'); the topic ‘Acute Kidney Injury on CKD’ was not included in the priority rating due to an administrative error. The moderator then summarized individual ratings by presenting the median and interquartile range (IQR), accompanied by a bar chart visualizing the rating frequency distribution. Subsequently, the group discussed topics for which priorities varied strongly among experts, and explored explanations for that variation. In round 2, we asked experts to individually and anonymously reconsider their round 1 ratings while taking into account the arguments which arose during the group discussions.

\section{Data analysis}

We ranked topics based on the median priority rating (largest to smallest) and its range (smallest to largest) across all experts, as assigned in the second round of the consensus meeting. The range reflected the difference between the highest and lowest rating assigned by individual experts. To calculate the degree of consensus on a topic's priority, we divided the 
9-point rating scale in seven, overlapping 3-point windows (1 to 3, 2 to 4, etc., up to 7 to 9), and counted the number of individual ratings within each window. The highest number of ratings within any of the 3-point windows determined the degree of consensus. This value could range from 4 to 12, with a degree of 12 implying full expert consensus. Differences in consensus degree between rounds were analysed descriptively. All analyses were performed using IBM SPSS Statistics for Windows version 20.0.0.1.

\section{Results}

In total, 107 geriatricians and 461 renal clinicians from 82 countries participated in the online consultation; our method of distribution did not allow us to ascertain a response rate. The results are presented in the Appendix B.

Table A displays the final priority ranking of topics resulting from the expert consensus meeting. The highest rating in the second round was assigned to 'Screening and referral' (8.5; range, 2). Eight topics shared the second highest rating with a median priority score of 8.0 (2), and included topics such as 'Starting dialysis or not'; 'Accurate assessment of renal function’; ‘Targets for and management of hypertension’; ‘Detection of causes for and treatment of weight loss and malnutrition'. 'Targets for and treatment of diabetes’ received the lowest rating with $(3.0 ; 6)$.

The number of topics with full consensus increased from three in the first to ten in the second round, of which nine were positioned in the priority top 10. Overall, the mean degree of consensus was 8.98 (SD, 1.58) out of 12 in round 1 , and increased to 9.61 (SD, 1.63) in round 2.

\section{Discussion}


This study identified and prioritized topics to be addressed in European guidelines for management of CKD in older patients. We identified 47 potential topics through a literature review and by consulting over 500 nephrologists and geriatricians. Through a standardised formal consensus procedure, an expert panel assigned highest priority to 'Screening and referral of older CKD patients’

\section{Priorities for guideline development}

In keeping with the top priority of screening and referral of older CKD patients, the guideline group intends to develop guidance on the use of prognostic scores to predict death and progression to end-stage renal disease; estimating prognosis was also considered important during the international consensus conference on supportive CKD care organized by KDIGO [13]. The focus for the European guidelines will be on identifying scores to distinguish between patients that may benefit from renal replacement therapy and those who may not $[14,15]$. How to integrate such scores in the decision to start dialysis (ranked $2^{\text {nd }}$ in our prioritization), and within a shared treatment decision-making process (ranked $10^{\text {th }}$ ) in general has been addressed by other guidelines $[13,16]$.

Use of prognostic markers to predict the likely course of the patient could enable agreement on criteria for interdisciplinary referral between nephrologists and geriatricians, and might overcome potential gaps between treatment paradigms in nephrology and geriatric medicine. Such referral criteria should ultimately be incorporated in guidance on how to organize care for older patients with CKD stage 3b-5, a topic that our expert panel ranked in the top 10 . The summary report of the conference on supportive CKD care [13] stated that such care should ideally be delivered by multi-professional teams, for example, during joint nephrologygeriatric clinics. Likewise, weight loss and malnutrition (assigned second highest priority) might best be addressed in a multidisciplinary setting. Nephrologists tend to focus on dietary needs whereas geriatricians also address factors such as mobility and cognition which affect 
ability to shop and prepare food. The advantages of a multi-professional approach notwithstanding, a recent study among European nephrologists and geriatricians suggested that geriatricians are currently seldom involved in dialysis withdrawal decisions, implying a substantial room for improvement in this regard [17].

Assessment of renal function was also assigned high priority for developing guidance. During group discussions, experts highlighted that the focus of this guidance should be on identifying equations to estimate the glomerular filtration rate, primarily to inform medication dose adjustments in older CKD patients. Suggested tests should be cheap and widely available, and not confounded by factors associated with age, such as reduced muscle mass [18].

For the final topic selection, the expert group decided against developing guidance for topics already covered by other guidelines. So, despite their high priority, the topics of withholding and withdrawing dialysis were not selected as they both had been addressed previously [13, 16, 20]. This in line with the international harmonisation effort among renal guideline bodies [19], and includes the expert consensus statement on supportive care by KDIGO [13]. KDIGO’s guidance development methodology differs from our approach by having expert consensus at its core supported by scoping reviews of the literature, whereas we opted for starting from systematic literature reviews complemented with expert consensus.

Topics such as management of uraemic pruritus were excluded from the prioritization beforehand because guidance was expected to be similar across CKD patients of all ages. The group acknowledged the high prevalence of this symptom [21] and its importance to patients [22], but deemed it more appropriate to explore the applicability of existing non-renal guidelines [23], or develop pruritus management guidelines targeting CKD stage 3b-5 patients in general.

$\underline{\text { Strengths and limitations }}$ 
As part of our methodological approach, we consulted an international group of nephrologists and geriatricians. This broad clinical representation limited the probability of missing topics considered clinically important for the management of CKD in older people; this probability was further decreased by reviewing the literature to inform the online clinician consultation. Furthermore, consulting both stakeholder groups enabled multidisciplinary involvement in the guideline development process, which is advocated for producing balanced guidance [11, 24].

The expert panel might have assigned high priority to the topic of 'Acute kidney injury on CKD' due to its relatively high incidence in old age, the increasing complexity of risk factors with advancing age, and its poor prognosis for renal function recovery [25]. However, we failed to formally prioritize the topic due to an administrative error. Another limitation of our study is that we did not involve patients or patient representatives. Previous research suggested that clinicians’ and patients’ perspectives may differ regarding what treatment decisions are important [26, 27]. Thus, involving (representatives of) older patients with CKD in our scoping process might have provided a complementary view of what topics deserve high priority for guideline development.

\section{$\underline{\text { Future steps }}$}

Following the topic selection described in this paper, the guideline development group is now in the process of systematically synthesising the best available evidence for the high priority topics. In keeping with previous research suggesting that randomised studies seldom include older patients [28], the group acknowledged that the strength of the evidence base for providing practice recommendation in this group of patients is sometimes limited. Some of the topics (see Table A) will therefore be addressed as 'pro-con debates' between experts (for example, dialysis modality selection [29] and optimising dialysis adequacy [30]). The systematic approach for evidence retrieval and synthesis will, however, reveal the most 
prominent knowledge gaps for CKD management in older patients, which will contribute to setting the European agenda for future research.

\section{Compliance with Ethical Standards}

This initiative was financially endorsed by the European Renal Association-European Dialysis and Transplant Association (ERA-EDTA). SV and IN are ERA-EDTA-funded research fellows working on renal guideline development as members of the Methods Support Team of European Renal Best Practice (http://european-renal-best-practice.org). All authors declare that they have no conflict of interest.

Informed consent was obtained from all experts participating in the study. The procedures performed in this study were in accordance with the ethical standards of the institutional research committee and with the 1964 Helsinki declaration and its later amendments. This article does not contain any studies with animals performed by any of the authors. 


\section{References}

1. ERA-EDTA (2014) ERA-EDTA Registry Annual Report 2012. Amsterdam, The Netherlands

2. Collins AJ, Foley RN, Chavers B, et al. (2014) US Renal Data System 2013 Annual Data Report. AJKD 63:A7. doi: 10.1053/j.ajkd.2013.11.001

3. Johansen KL, Chertow GM, Jin C, Kutner NG (2007) Significance of frailty among dialysis patients. J Am Soc Nephrol 18:2960-7. doi: 10.1681/ASN.2007020221

4. O’Hare AM, Kaufman JS, Covinsky KE, et al. (2009) Current Guidelines for Using Angiotensin-Converting Enzyme Inhibitors and Angiotensin II - Receptor Antagonists in Chronic Kidney Disease : Is the Evidence Base Relevant to Older Adults? 150:

5. Bowling CB, Booth JN, Gutiérrez OM, et al. (2014) Nondisease-Specific Problems and All-Cause Mortality among Older Adults with CKD: The REGARDS Study. Clin J Am Soc Nephrol 9:1737-45. doi: 10.2215/CJN.00880114

6. Da Silva-Gane M, Wellsted D, Greenshields H, et al. (2012) Quality of life and survival in patients with advanced kidney failure managed conservatively or by dialysis. Clin J Am Soc Nephrol 7:2002-9. doi: 10.2215/CJN.01130112

7. DeSilva RN, Patibandla BK, Vin Y, et al. (2013) Fistula first is not always the best strategy for the elderly. J Am Soc Nephrol 24:1297-304. doi: 10.1681/ASN.2012060632

8. Cox L, Kloseck M, Crilly R, et al. (2011) Underrepresentation of individuals 80 years of age and older in chronic disease clinical practice guidelines. Can Fam Physician 57:e263-9.

9. Blozik E, Dubben HH, Wagner HO, Scherer M (2014) Comorbidity in medical guidelines: comparison of the current state, epidemiologic models and expert opinion [article in German]. Z Evid Fortbild Qual Gesundhwes 108:219-228. doi: 10.1016/j.zefq.2014.02.001

10. Brouwers MC, Kho ME, Browman GP, et al. (2010) AGREE II: advancing guideline development, reporting and evaluation in health care. J Clin Epidemiol 63:1308-11. doi: 10.1016/j.jclinepi.2010.07.001

11. Eccles MP, Grimshaw JM, Shekelle P, et al. (2012) Developing clinical practice guidelines: target audiences, identifying topics for guidelines, guideline group composition and functioning and conflicts of interest. Implement Sci 7:60. doi: 10.1186/1748-5908-7-60

12. Murphy M, Black N, Lamping D, et al. (1998) Consensus development methods, and their use in clinical guideline development. Health Technol. Assess. (Rockv). 2:

13. Davison SN, Levin A, Moss AH, et al. (2015) Executive summary of the KDIGO Controversies Conference on Supportive Care in Chronic Kidney Disease: developing a roadmap to improving quality care. Kidney Int 447-459. doi: 10.1038/ki.2015.110

14. Couchoud CG, Beuscart J-BR, Aldigier J-C, et al. (2015) Development of a risk stratification algorithm to improve patient-centered care and decision making for incident elderly patients with end-stage renal disease. Kidney Int 88:1178-1186. doi: 10.1038/ki.2015.245 
15. Thamer M, Kaufman J, Zhang Y, et al. (2015) Predicting Early Death Among Elderly Dialysis Patients: Development and Validation of a Risk Score to Assist Shared Decision Making for Dialysis Initiation. Am J Kidney Dis 66:1024-1032.

16. Renal Physicians Association (2010) Clinical Practice Guideline on Shared DecisionMaking in the Appropriate Initiation of and Withdrawal from Dialysis (2nd edition). Available from www.renalmd.org.

17. van Biesen W, van de Luijtgaarden MWM, Brown EA, et al. (2015) Nephrologists' perceptions regarding dialysis withdrawal and palliative care in Europe: lessons from a European Renal Best Practice survey. Nephrol Dial Transplant [ePub ahead of print]. doi: 10.1093/ndt/gfv284

18. Lopes MB, Araújo LQ, Passos MT, et al. (2013) Estimation of glomerular filtration rate from serum creatinine and cystatin $\mathrm{C}$ in octogenarians and nonagenarians. BMC Nephrol 14:265. doi: 10.1186/1471-2369-14-265

19. Haller MC, van der Veer SN, Nagler E V, et al. (2014) A survey on the methodological processes and policies of renal guideline groups as a first step to harmonize renal guidelines. Nephrol Dial Transplant [ePub ahead of print]. doi: 10.1093/ndt/gfu288

20. Douglas C, Murtagh FEM, Chambers EJ, et al. (2009) Symptom management for the adult patient dying with advanced chronic kidney disease: a review of the literature and development of evidence-based guidelines by a United Kingdom Expert Consensus Group. Palliat Med 23:103-10. doi: 10.1177/0269216308100247

21. Weiss M, Mettang T, Tschulena U, et al. (2015) Prevalence of Chronic Itch and Associated Factors in Haemodialysis Patients: A Representative Cross-sectional Study. Acta Derm Venereol 95:816-821. doi: 10.2340/00015555-2087

22. Manns B, Hemmelgarn B, Lillie E, et al. (2014) Setting research priorities for patients on or nearing dialysis. Clin J Am Soc Nephrol 9:1813-21. doi: 10.2215/CJN.01610214

23. Weisshaar E, Szepietowski J, Darsow U, et al. (2014) European Dermatology Forum Update of the Guideline on Chronic Pruritus. European Dermatology Forum

24. Graham R, Mancher M, Wolman DM, et al. (2011) Institute of Medicine: Clinical Practice Guidelines We Can Trust. Natl Acad Press 1-13.

25. Kane-Gill SL, Sileanu FE, Murugan R, et al. (2015) Risk Factors for Acute Kidney Injury in Older Adults With Critical Illness: A Retrospective Cohort Study. Am J kidney Dis 65:860-869. doi: 10.1053/j.ajkd.2014.10.018

26. Voigt I, Wrede J, Diederichs-Egidi H, et al. (2010) Priority Setting in General Practice: Health Priorities of Older Patients Differ from Treatment Priorities of Their Physicians. Croat Med J 51:483-492. doi: 10.3325/cmj.2010.51.483

27. van der Veer SN, Haller MC, Pittens C a. CM, et al. (2015) Setting Priorities for Optimizing Vascular Access Decision Making - An International Survey of Patients and Clinicians. PLoS One 10:e0128228. doi: 10.1371/journal.pone.0128228

28. Zulman DM, Sussman JB, Chen X, et al. (2011) Examining the evidence: a systematic review of the inclusion and analysis of older adults in randomized controlled trials. $\mathrm{J}$ Gen Intern Med 26:783-90. doi: 10.1007/s11606-010-1629-x

29. Segall L, Nistor I, Van Biesen W, et al. (2015) Dialysis modality choice in elderly 
patients with end-stage renal disease: a narrative review of the available evidence. Nephrol. Dial. Transplant. [in press]:

30. Chazot C, Farrington K, Nistor I, et al. (2015) Pro and con arguments in using alternative dialysis regimens in the frail and elderly patients. Int Urol Nephrol 47:1809-1816. doi: 10.1007/s11255-015-1107-9 
Table A Priority ranking of topics for being covered in the new European guidelines on managing CKD in older patients

\begin{tabular}{|c|c|c|c|c|c|c|}
\hline \multirow[b]{2}{*}{ Rank $^{\text {a) }}$} & \multirow[b]{2}{*}{ Topic } & \multirow[b]{2}{*}{ Category } & \multicolumn{2}{|c|}{ Round 1} & \multicolumn{2}{|c|}{ Round 2} \\
\hline & & & $\begin{array}{c}\text { Median } \\
\text { (range }{ }^{b)} \text { ) }\end{array}$ & $\begin{array}{c}\text { Consensus } \\
\text { degree } c^{c}\end{array}$ & $\begin{array}{r}\text { Median } \\
\left.\text { (range }{ }^{b)}\right)\end{array}$ & $\begin{array}{c}\begin{array}{c}\text { Consensus } \\
\left.\text { degree }{ }^{c}\right)\end{array} \\
\end{array}$ \\
\hline 1 & Screening and referral of older CKD patients ${ }^{d)}$ & General patient management & $8.0(3)$ & 10 & $8.5(2)$ & 12 \\
\hline \multirow[t]{8}{*}{2} & Starting dialysis or not (withholding) & Decisions around treatment selection & $8.0(3)$ & 10 & $8.0(2)$ & 12 \\
\hline & Accurate assessment of renal function & Assessment of renal function & $7.5(6)$ & 8 & $8.0(2)$ & 12 \\
\hline & Hypertension management (blood pressure targets, treatment) & Management of comorbidities & $7.5(2)$ & 12 & $8.0(2)$ & 12 \\
\hline & Organization of care for older CKD patients ${ }^{\mathrm{e}}$ & General patient management & $7.0(3)$ & 11 & $8.0(2)$ & 12 \\
\hline & $\begin{array}{l}\text { Changes in dietary regimen and fluid management as part of } \\
\text { conservative management }\end{array}$ & Conservative management of ESRD & $8.0(2)$ & 12 & $8.0(2)$ & 12 \\
\hline & Fluid status management (including cardio-renal problems) & Management of comorbidities & $7.5(2)$ & 12 & $8.0(2)$ & 12 \\
\hline & Weight loss and malnutrition (detection of causes and treatment) & Management of symptoms & $7.0(6)$ & 9 & $8.0(2)$ & 12 \\
\hline & When to start dialysis & Renal Replacement Therapy & $7.5(3)$ & 10 & $8.0(2)$ & 12 \\
\hline \multirow[t]{2}{*}{10} & General treatment decision-making process ${ }^{f)}$ & Decisions around treatment selection & $8.0(3)$ & 10 & $8.0(3)$ & 11 \\
\hline & Selecting dialysis modality g) & Renal Replacement Therapy & $7.0(4)$ & 9 & $8.0(3)$ & 10 \\
\hline 12 & $\begin{array}{l}\text { Psychosocial support (needs assessment, interventions) as part of } \\
\text { conservative management }\end{array}$ & Conservative management of ESRD & $8.0(4)$ & 11 & $8.0(4)$ & 11 \\
\hline \multirow[t]{3}{*}{13} & Continuing dialysis or not (withdrawal) & Decisions around treatment selection & $8.0(4)$ & 10 & $8.0(6)$ & 11 \\
\hline & Geriatric assessment tools and scoring systems & General patient management & $7.5(7)$ & 7 & $8.0(6)$ & 10 \\
\hline & General prevention of decline of renal function & Assessment of renal function & $7.5(4)$ & 10 & $8.0(6)$ & 10 \\
\hline 16 & $\begin{array}{l}\text { Psychosocial support (needs assessment, interventions) in patients on } \\
\text { RRT }\end{array}$ & Renal Replacement Therapy & $7.0(3)$ & 11 & $7.5(2)$ & 12 \\
\hline 17 & Diagnostic approach for frailty syndrome & Management of symptoms & $7.0(6)$ & 9 & $7.5(6)$ & 9 \\
\hline 18 & Functional status and mobility (assessment and prevention of decline) & Management of symptoms & $7.0(6)$ & 9 & $7.0(4)$ & 11 \\
\hline \multirow[t]{2}{*}{19} & Opting for transplantation or not ${ }^{\mathrm{g}}$ & Decisions around treatment selection & $7.0(4)$ & 9 & $7.0(5)$ & 9 \\
\hline & $\begin{array}{l}\text { Management of cognitive function (assessment, prevention of decline } \\
\text { and treatment) }\end{array}$ & Management of symptoms & $7.0(4)$ & 9 & $7.0(5)$ & 10 \\
\hline
\end{tabular}


Table A (continued)

\begin{tabular}{|c|c|c|c|c|c|c|}
\hline \multirow[b]{2}{*}{$\operatorname{Rank}^{\text {a) }}$} & \multirow[b]{2}{*}{ Topic } & \multirow[b]{2}{*}{ Category } & \multicolumn{2}{|c|}{ Round 1} & \multicolumn{2}{|c|}{ Round 2} \\
\hline & & & $\begin{array}{c}\text { Median } \\
\text { (range }^{\text {b) }} \text { ) }\end{array}$ & $\begin{array}{c}\text { Consensus } \\
\text { degree }^{c}\end{array}$ & $\begin{array}{c}\text { Median } \\
\text { (range }^{\text {b) }} \text { ) }\end{array}$ & $\begin{array}{c}\text { Consensus } \\
\text { degree }^{c}\end{array}$ \\
\hline 21 & Changes in pharmacological treatment & Conservative management of ESRD & $7.0(4)$ & 10 & $7.0(6)$ & 9 \\
\hline 22 & Dietary management ${ }^{\mathrm{d})}$ & General patient management & $7.0(8)$ & 7 & $7.0(8)$ & 10 \\
\hline 23 & Prognosis of older CKD patients d) & General patient management & $7.0(5)$ & 10 & $6.5(4)$ & 8 \\
\hline 24 & General approach to treat other underlying kidney diseases & Assessment of renal function & $7.0(5)$ & 8 & $6.5(5)$ & 9 \\
\hline 25 & Management of mineral bone disease and fracture risk ${ }^{\mathrm{h}}$ ) & Management of comorbidities & $7.0(4)$ & 11 & $6.5(7)$ & 9 \\
\hline 26 & Timing of conversation about opting for RRT or conservative care & Decisions around treatment selection & $7.5(8)$ & 8 & $6.5(8)$ & 9 \\
\hline 27 & $\begin{array}{l}\text { Management renal anaemia (diagnostic approach, haemoglobin } \\
\text { targets, treatment) }\end{array}$ & Management of comorbidities & $6.5(6)$ & 7 & $6.0(5)$ & 10 \\
\hline \multirow[t]{2}{*}{28} & Assessment of symptom burden & Management of symptoms & $7.0(6)$ & 9 & $6.0(6)$ & 9 \\
\hline & Management of geriatric syndromes d) & Management of symptoms & $7.0(6)$ & 8 & $6.0(6)$ & 8 \\
\hline \multirow[t]{5}{*}{30} & Kidney transplantation g) & Renal Replacement Therapy & $6.5(7)$ & 8 & $6.0(7)$ & 9 \\
\hline & Treatment of depression & Management of symptoms & $6.0(6)$ & 10 & $6.0(7)$ & 8 \\
\hline & Management of polypharmacy & Management of comorbidities & $7.0(3)$ & 10 & $6.0(7)$ & 9 \\
\hline & Advance directives ${ }^{\text {i) }}$ & General patient management & $6.5(7)$ & 7 & $6.0(7)$ & 8 \\
\hline & Optimising dialysis adequacy/quality g) & Renal Replacement Therapy & $6.5(5)$ & 8 & $6.0(7)$ & 9 \\
\hline 35 & Selection of vascular access type and site & Renal Replacement Therapy & $6.0(5)$ & 7 & $5.5(7)$ & 7 \\
\hline \multirow[t]{2}{*}{36} & Pain assessment and control & Management of symptoms & $6.5(4)$ & 9 & $5.0(6)$ & 9 \\
\hline & Do-Not-Resuscitate / Allow-Natural-Death order j) & General patient management & $5.0(7)$ & 5 & $5.0(6)$ & 9 \\
\hline 38 & Treatment of arteriosclerotic vascular disease & Management of comorbidities & $7.0(5)$ & 10 & $5.0(7)$ & 7 \\
\hline \multirow[t]{2}{*}{39} & Treatment of electrolyte disorders & Management of symptoms & $6.5(6)$ & 9 & $4.5(6)$ & 8 \\
\hline & $\begin{array}{l}\text { Diagnostic approach for malnutrition-inflammation-atherosclerosis } \\
\text { (MIA) syndrome }\end{array}$ & Management of symptoms & $6.5(5)$ & 8 & $4.5(6)$ & 8 \\
\hline
\end{tabular}


Table A (continued)

\begin{tabular}{|c|c|c|c|c|c|c|}
\hline \multirow[b]{2}{*}{$\operatorname{Rank}^{\text {a) }}$} & \multirow[b]{2}{*}{ Topic } & \multirow[b]{2}{*}{ Category } & \multicolumn{2}{|c|}{ Round 1} & \multicolumn{2}{|c|}{ Round 2} \\
\hline & & & $\begin{array}{c}\text { Median } \\
\text { (range }^{\text {b) }} \text { ) }\end{array}$ & $\begin{array}{c}\text { Consensus } \\
\text { degree }^{\text {c) }}\end{array}$ & $\begin{array}{c}\text { Median } \\
\left(\text { (range }^{\text {b) }}\right)\end{array}$ & $\begin{array}{c}\text { Consensus } \\
\text { degree }^{c}\end{array}$ \\
\hline 41 & Quality of life - methods of assessment and monitoring & General patient management & $6.0(6)$ & 7 & $4.5(6)$ & 6 \\
\hline 42 & Diagnostic approach for identifying underlying kidney disease & Assessment of renal function & $5.0(6)$ & 7 & $4.0(4)$ & 9 \\
\hline 43 & Treatment of delirium & Management of symptoms & $5.5(7)$ & 8 & $3.5(5)$ & 7 \\
\hline \multirow[t]{2}{*}{44} & Treatment of infectious diseases & Management of comorbidities & $4.5(7)$ & 6 & $3.0(4)$ & 9 \\
\hline & Targets for cholesterol management & Management of comorbidities & $4.0(6)$ & 9 & $3.0(4)$ & 9 \\
\hline 46 & Diabetes management (blood glucose targets, treatment) & Management of comorbidities & $6.0(7)$ & 9 & $3.0(6)$ & 8 \\
\hline j) & Acute Kidney Injury on CKD d) & & k) & & k) & \\
\hline
\end{tabular}

Abbreviations: CKD, chronic kidney disease; ESRD, end-stage renal disease; RRT, renal replacement therapy

a) Based on the mean (SD) priority ratings as assigned by experts in round 2 of the consensus meeting

b) The range reflects the difference between the highest and the lowest rating assigned by individual experts

c) Consensus degrees could range between 3 and 12

d) New topics added based on suggestions from open consultation

e) For example, multidisciplinary approach, communication between primary and secondary care

f) For example, decision aids, involvement of family and carers, educational interventions

g) This topic will be addressed in a 'pro-con debate' between experts

h) Includes diagnostic approach, targets for parameters of mineral bone disorder, treatment, fall and fracture prevention

i) Defined as written instruction to (withdraw or withhold) treatment if the patient is no longer able to decide himself

j) Defined as legal order to respect the patient's wish not to be resuscitated in case of asystole or apnea

k) ‘Acute Kidney Injury on CKD' was identified as a potential guideline topic, but not included in the priority rating due to an administrative error 


\section{Appendix A: Search strategy for scoping review of the literature}

Medline via OVID

1. Kidney Diseases/

2. exp Renal Replacement Therapy/

3. Renal Insufficiency/

4. exp Renal Insufficiency, Chronic/

5. dialysis.tw.

6. (hemodialysis or haemodialysis).tw.

7. (hemofiltration or haemofiltration).tw.

8. (hemodiafiltration or haemodiafiltration).tw.

9. (end-stage renal or end-stage kidney or endstage renal or endstage kidney).tw.

10. (ESRF or ESKF or ESRD or ESKD).tw.

11. (chronic kidney or chronic renal).tw.

12. (CKF or CKD or CRF or CRD).tw.

13. (CAPD or CCPD or APD).tw.

14. (predialysis or pre-dialysis).tw.

15. or $/ 1-14$

16. Elderly.tw.

17. community-dwelling.tw.

18. geriatric.tw.

19. mini-mental state.tw.

20. alzheimer*.tw.

21. mmse.tw.

22. caregivers.tw.

23. falls.tw.

24. Adl.tw.

25. Frailty.tw.

26. Gds.tw.

27. Ageing.tw.

28. hip fractures.tw. 
29. elders.tw.

30. Frail*.tw.

31. Mci.tw.

32. Demented.tw.

33. Psychogeriatrics.tw.

34. cognitive impairment.tw.

35. postmenopausal women.tw.

36. dementia.tw.

37. aging.tw.

38. older.tw.

39. or $/ 16-38$

40. 15 and 39

Cochrane's central register of controlled trials (CENTRAL)

\#1 dialysis:ti,ab,kw

\#2 h*emofiltration:ti,ab,kw

\#3 h*emodiafiltration:ti,ab,kw

\#4 (end-stage renal or end-stage kidney or endstage renal or endstage kidney):ti,ab,kw

\#5 (ESRF or ESKF or ESRD or ESKD):ti,ab,kw

\#6 (chronic kidney or chronic renal):ti,ab,kw

\#7 (CKF or CKD or CRF or CRD):ti,ab,kw

\#8 (CAPD or CCPD or APD):ti,ab,kw

\#9 (predialysis or pre-dialysis):ti,ab,kw

\#10 MeSH descriptor: [Kidney Failure, Chronic] this term only

\#11 MeSH descriptor: [Renal Replacement Therapy] explode all trees

\#12 MeSH descriptor: [Renal Insufficiency, Chronic] explode all trees

$\# 13 \# 1$ or \#2 or \#3 or \#4 or \#5 or \#6 or \#7 or \#8 or \#9 or \#10 or \#11 or \#12

\#14 Aged, 80 and over

\#15 Frail Elderly

\#16 \#14 or \#15

\#17 \#13 and \#16 
Appendix B - Priorities for guideline development from online consultation among clinicians; values represent number (\%) of respondents who selected a topic ${ }^{\text {a) }}$

\begin{tabular}{|c|c|c|}
\hline Topic & $\begin{array}{c}\text { Geriatricians } \\
(\mathrm{n}=107)\end{array}$ & $\begin{array}{c}\text { Renal clinicians } \\
(\mathrm{n}=461)\end{array}$ \\
\hline \multicolumn{3}{|l|}{ PATIENTS WITH ADVANCED CHRONIC KIDNEY DISEASE (PRE-ESRD PHASE) } \\
\hline \multicolumn{3}{|l|}{ Category 1: Assessment of renal function and diagnosis of renal impairment } \\
\hline Accurate assessment of renal function (e.g., eGFR, urinary protein estimation) & $66(62)$ & $182(40)$ \\
\hline General prevention of decline of renal function & $61(57)$ & $314(68)$ \\
\hline Diagnostic approach for identifying underlying kidney disease (e.g., urinalysis, renal biopsy, magnetic resonance angiography, ultrasonography) & $38(36)$ & 154( 33$)$ \\
\hline Treatment of glomerulonephritis & $4(4)$ & $30(7)$ \\
\hline General approach to treat other underlying kidney diseases and delay progression & $45(42)$ & $242(53)$ \\
\hline \multicolumn{3}{|l|}{ Category 2: Management of symptoms related to advanced CKD } \\
\hline Assessment of symptom burden & $69(65)$ & $267(58)$ \\
\hline Diagnostic approach for frailty syndrome & $53(50)$ & $209(45)$ \\
\hline Diagnostic approach for MIA syndrome & $23(22)$ & $243(53)$ \\
\hline Pain assessment and control & $39(36)$ & $235(51)$ \\
\hline Weight loss and malnutrition (detection of causes and treatment) & $79(74)$ & $308(67)$ \\
\hline Functional status and mobility (assessment and prevention of decline) & 95 (89) & $358(78)$ \\
\hline Cognitive function (assessment and prevention of decline) & $57(53)$ & $244(53)$ \\
\hline Treatment of cognitive impairment & $13(12)$ & $88(19)$ \\
\hline Delirium and depression (diagnostic approach and treatment) & $39(36)$ & $91(20)$ \\
\hline Treatment of electrolyte disorders (e.g., hyperkalemia, hyponatremia) & $68(64)$ & $262(57)$ \\
\hline \multicolumn{3}{|l|}{ Category 3: Management of comorbidities } \\
\hline Hypertension management (blood pressure targets, treatment) & $84(79)$ & $376(82)$ \\
\hline Targets for cholesterol management & $5(5)$ & $46(10)$ \\
\hline Diabetes management (blood glucose targets, treatment) & $71(66)$ & $281(61)$ \\
\hline
\end{tabular}


Appendix B (continued)

\begin{tabular}{|c|c|c|}
\hline Topic & $\begin{array}{c}\text { Geriatricians } \\
\quad(\mathrm{n}=107)\end{array}$ & $\begin{array}{c}\text { Renal clinicians } \\
(\mathrm{n}=461)\end{array}$ \\
\hline Fluid status assessment & $66(56)$ & $296(64)$ \\
\hline Treatment of cardiovascular disease (e.g., anticoagulants, exercise) & $60(56)$ & $310(67)$ \\
\hline Treatment of vascular disease (e.g., pharmacological therapy, interventional surgery) & $19(18)$ & $121(26)$ \\
\hline Management of mineral bone disease and fracture risk (diagnostic approach, targets, treatment, fracture risk) & $50(47)$ & $235(51)$ \\
\hline Anemia management (hemoglobin targets, treatment) & $78(73)$ & $278(60)$ \\
\hline Treatment of infectious diseases & $26(24)$ & $100(22)$ \\
\hline Management of polypharmacy (e.g., Potentially Inappropriate Medication (PIM) lists, prevention of adverse drug events) & $76(71)$ & $262(57)$ \\
\hline \multicolumn{3}{|l|}{ PATIENTS WITH END-STAGE RENAL DISEASE } \\
\hline \multicolumn{3}{|l|}{ Category 4: Decisions around treatment selection } \\
\hline Geriatric assessment tools and scoring systems & $63(59)$ & $130(28)$ \\
\hline Quality of life - methods of assessment and monitoring & $60(56)$ & $283(61)$ \\
\hline Timing of the conversation about the treatment decision to opt for RRT or conservative care & $52(49)$ & $263(57)$ \\
\hline Starting dialysis or not (withholding) & $52(49)$ & $307(67)$ \\
\hline Continuing dialysis or not (withdrawal) & $21(20)$ & $130(28)$ \\
\hline Opting for transplantation or not & $10(9)$ & $72(16)$ \\
\hline Decision making process (e.g., shared decision making aids, involvement of family and carers) & $63(59)$ & $198(43)$ \\
\hline \multicolumn{3}{|l|}{ Category 5: Renal replacement therapy } \\
\hline Timing of dialysis (when to start dialysis) & $83(78)$ & $380(82)$ \\
\hline Selecting dialysis modality (e.g., in-center haemodialysis, assisted peritoneal dialysis) & $75(70)$ & $382(83)$ \\
\hline Optimizing dialysis adequacy/quality & $63(59)$ & $207(45)$ \\
\hline Selection of vascular access type (e.g., permanent catheter, arteriovenous fistula) & $39(36)$ & $340(74)$ \\
\hline Selection of vascular access site & $11(10)$ & $88(19)$ \\
\hline
\end{tabular}


Appendix B (continued)

\begin{tabular}{|c|c|c|}
\hline Topic & $\begin{array}{l}\text { Geriatricians } \\
(\mathrm{n}=107)\end{array}$ & $\begin{array}{c}\text { Renal clinicians } \\
(\mathrm{n}=461)\end{array}$ \\
\hline Kidney transplantation (e.g., recipient work-up, post-transplant management, type of immunosuppression) & $20(19)$ & $98(21)$ \\
\hline Psycho-social support (needs assessment and interventions) & $74(69)$ & $310(67)$ \\
\hline Organisation of palliative care (processes and resources needed for good palliative care) & $56(52)$ & $189(41)$ \\
\hline Advance directives (written instructions to (withdraw or withhold) treatment if the patient is no longer able to decide himself) & $69(64)$ & $184(40)$ \\
\hline Do-Not-Resuscitate / Allow-Natural-Death order (legal order to respect the wish of a patient not to be resuscitated in case of asystole or apnea) & $45(42)$ & $127(28)$ \\
\hline \multicolumn{3}{|l|}{ Category 6: Conservative (non-dialytic) management of ESRD } \\
\hline Changes in dietary regimen and fluid management compared to pre-ESRD phase & $54(51)$ & $340(74)$ \\
\hline Changes in pharmacological treatment compared to pre-ESRD phase & $71(66)$ & $291(63)$ \\
\hline Psycho-social support (needs assessment and interventions) & $51(48)$ & $280(61)$ \\
\hline Organisation of palliative care (processes and resources needed for good palliative care) & $63(59)$ & $250(54)$ \\
\hline Advance directives (written instructions to (withdraw or withhold) treatment if the patient is no longer able to decide himself) & $52(49)$ & $130(28)$ \\
\hline Do-Not-Resuscitate / Allow-Natural-Death order (legal order to respect the wish of a patient not to be resuscitated in case of asystole or apnea) & $30(28)$ & $92(20)$ \\
\hline
\end{tabular}

Abbreviations: eGFR, estimated glomerular filtration rate; ESRD, end-stage renal disease; MIA, malnutrition-inflammation-atherosclerosis

a) Per category, we asked respondents which topics should be assigned highest priority for inclusion in the guideline. They had to select exactly $50 \%$ of the topics within a category, or (50\% - 0.5) for categories containing an odd numbers of topics.

b) The large majority $(n=450)$ were practicing as a nephrologist. 